\title{
НАСКОЛЬКО РЕАЛЬНО «ИЗБАВИТЬСЯ ОТ СТЕРЕОТИПОВ»? (ПОЛЕМИЧЕСКИЕ ЗАМЕТКИ НА ПОЛЯХ ПУБЛИКАЦИЙ ПО ПРОБЛЕМАМ ТЕОРИИ МЕЖКУЛЬТУРНОЙ КОММУНИКАЦИИ)
}

\author{
Л. И. Гришаева
}

Воронежский государственный университет

\section{HOW REALISTIC IS IT TO “GET RID OF STEREOTYPES”? (POLEMIC NOTES IN THE MARGINS OF PUBLICATIONS ON THE MAJOR ISSUES OF THE THEORY OF INTERCULTURAL COMMUNICATION)}

\author{
L. I. Grishaeva \\ Voronezh State University
}

\begin{abstract}
Аннотация: в статье лаконично обсуждаются отдельные тезисы, воспринимаемые во многих версиях теории межкультурной коммуникации, а также в ряде гуманитарных наук, как правило, в качестве аксиоматичных и в силу этого основополагающих для углубленных рассуждений в названном проблемном поле. Обсуждается одно из возможных объяснений сложивщегося положения дел, имеющего широкое распространение. Анализируются причины, обусловливающие активное хождение соответствующих тезисов при изучении общих и частных теоретически значимых, а также прикладных вопросов теории межкультурной коммуникации. Обращается внимание на потенциильную опасность описанных аберраций как для теоретического и прикладного изучения проблемного поля, так и для реальных межкультурных контактов. Называются основания, по которым предельно общие по содержанию и по форме акцентированно гуманистические рекомендации, в принципе нацеленные на оптимизацию межскультурного взаимодействия, оказываются, по сути, в реальности малоэффективными и вводящими в добросовестное заблуждение различные категории потенияильных потребителей подобных рекомендаций. Делается попытка найти конструктивное решение актуальных теоретических и прикладных задач.
\end{abstract}

Ключевые слова: барьеры в межкультурной коммуникации, ксенофобия, культурная идентичность, культурные коды, картина мира, мировосприятие, культурная сенситивность.

\begin{abstract}
: the article briefly discusses a number of ideas that are accepted in many versions of the theory of intercultural communication, as well as in a number of humanities, as a rule, as axiomatic and, therefore, fundamental for in-depth reasoning in these problem fields. One of the possible explanations of the current widespread state of affairs is discussed. The article analyses the reasons for the active use of the discussed ideas in the study of general and particular theoretical and applied issues of the theory of intercultural communication. Attention is drawn to the potential danger of the described aberrations for both the theoretical and applied studies within the field of intercultural communication, as well as for real-life intercultural contacts. There are reasons why extremely general in content and in form, accentuated humanistic recommendations, which are aimed at optimizing intercultural interaction, are, in fact, not very effective in reality and mislead in good faith various categories of potential consumers of such recommendations. An attempt is made to find a constructive solution to current theoretical and applied problems.
\end{abstract}

Key words: barriers in intercultural communication, xenophobia, cultural identity, cultural codes, worldview, world perception, cultural sensitivity.

(С Гришаева Л. И., 2021

Контент доступен под лицензией Creative Commons Attribution 4.0 License. The content is available under Creative Commons Attribution 4.0 License. 


\section{Постановка проблемы}

Прошло довольно много времени с тех пор, как теория межкультурной коммуникации (или введение в теорию межкультурной коммуникации) стала неотъемлемой составной частью академической подготовки по различным направлениям, прежде всего, на языковых факультетах. Появилось значительное количество изданий, претендующих на обобщение представлений относительно общих и частных проблем из соответствующей тематической области. Уже имеется богатый и позитивный, и негативный опыт, нуждающийся в глубоком осмыслении, чтобы способствовать дальнейшему развитию научного исследования названной проблематики, а также преподаванию академической дисциплины. Проводятся конференции, программы которых фокусируются на названной проблематике, обсуждаемой согласно разным постулатам и под разными углами зрения. Однако по-прежнему некритично тиражируются воззрения, восходящие к своим истокам в самых первых исследованиях в обозначенной сфере.

Недавно у меня был семинар по теории межкультурной коммуникации, и студенты на полном серьезе убеждали меня и своих сокурсников в том, что «у носителей разных культур разное мировосприятие». Однако разумных и/или внятных аргументов в защиту своей позиции они не могли привести, равно как и грамотно опровергнуть противоположную точку зрения - они лишь более или менее полно цитировали прочитанные ими при подготовке к семинару труды по изучаемой проблематике.

Такое положение дел весьма расстроило меня и побудило к двум действиям. Во-первых, стало ясно, что целесообразно несколько изменить логику преподавания предмета и акцентированно излагать свою позицию относительно обсуждаемых проблем. Вместе с тем очевидной стала необходимость обратить внимание студенческой аудитории на те или иные несоответствия между сущностью рассматриваемых феноменов и способами проговаривания обсуждаемых проблем, как они сложились по тем или иным причинам в научной среде. Во-вторых, трудно было не признать настоятельной потребности тематизировать в научной сфере названную проблематику и предложить заинтересованным лицам предметную дискуссию, итогом которой стало бы осмысление на новом витке познания проблем, критический взгляд на которые, как очевидно, уже замылился или же начал замыливаться.

Поэтому в качестве наиболее существенных задач данной статьи можно сформулировать следующие:

- предложить объяснение несоответствия между гуманными и гуманистическими общечеловеческими установками при изучении проблемного поля теории межкультурной коммуникации, с одной стороны, и отсутствием эффективной технологии их внедрения в социальную практику, т. е. тем самым отсутствием объяснительной силы принимаемых постулатов для реальной практики межкультурного взаимодействия, - с другой;

- проанализировать причины сложившегося положения дел, вступающего в очевидное противоречие с довольно длительной - по современным меркам - историей научного изучения названной проблематики.

Актуальность предлагаемой постановки изучаемого вопроса трудно подвергнуть сомнению, так как современные события в разных культурных пространствах богаты многочисленными и разнообразными примерами ксенофобии, нетолерантности, явной и желаемой конфликтности, наблюдаемых в разных культурных пространствах и в разных социумах, а также откровенной беспомощности теоретиков и практиков в области межкультурного взаимодействия, повторяющих, как заклинание, свои тезисы, несмотря на их очевидный для непредвзятого наблюдателя контраст с реальной действительностью. Особенно наглядно описанная ситуация проявляется в медиасреде, причем с разной интенсивностью в ее различных сегментах, в политической коммуникации, а также в публицистическом дискурсе и даже в разных форматах дипломатического и парламентского дискурсов.

Поэтому складывается впечатление, что дифференцированное знание о сущности межкультурной коммуникации, об особенностях обработки сведений о мире, воспринимаемых в одном и том же пространственно-временном континууме носителями разных культур, о способах и средствах решения одной и той же коммуникативной и когнитивной задачи носителями разных культур и др., полученное в процессе становления и развития теории межкультурной коммуникации как науки, сознательно и расчетливо используется для достижения в краткосрочной и долгосрочной перспективе разнообразных - порой неблаговидных - целей. Достаточно упомянуть некоторые из них, которые, судя по результатам, оказались довольно успешно реализуемыми и предсказуемыми: конструирование и поддержание в длительной временной перспективе фейков, эксплуатация предубеждений и предрассудков, создание и воспроизводство симулякров, поддержание позитивного имиджа единичного и коллективного субъекта в негативном для последних контексте, реализация в долговременной перспективе стратегий по дискредитации некоторого единичного и/или коллективных субъектов, конструирование позитива за счет акцентирования и гиперболизации реального и виртуального негатива как применительно к действиям единичного субъекта, так и коллективного субъекта и т. п. 
Поскольку образцы решения названных выше задач оказываются, как показывает практика, вполне эффективными на протяжении длительного времени, они по понятным причинам остаются предсказуемо востребованными прежде всего в медиасреде (ср. анализ разнообразных факторов, способствующих эффективности манипулятивного воздействия на носителей культуры в [1-3]). Поэтому-то необходимо осмыслить, какие из закономерностей, значимых для постижения феномена «межкультурная коммуникация», могут быть злонамеренно - сознательно и/или неосознанно - использоваться при достижении той или иной цели с ориентацией на конкретную категорию коммуникантов. Ср. в этой связи мнение Г. Антоса, который, анализируя конструирование фейков в медиапространстве, подчеркивает особую значимость коллективных представлений, норм ожиданий, свободного владения конвенциональными способами организации и осуществления коммуникации и др., присущими носителям культуры как адресатам соответствующих фейков [4]. Подобные задачи, вне всякого сомнения, не могут не влиять на способы использования языковых средств и как следствие - на организацию текстов разных типов (ср. соответствующие рассуждения в [5]).

\section{Материал исследования}

Материалом для исследования послужили четыре группы источников: во-первых, актуальные публикации по различным проблемам теории межкультурной коммуникации, выполненные согласно разным теоретическим воззрениям; во-вторых, учебники и учебные пособия, подготовленные в разные периоды формирования и становления теории межкультурной коммуникации как академической дисциплины; в-третьих, доклады и выступления на разные темы, значимые для теории межкультурной коммуникации, дискуссии в кулуарах конференций, вопросы к докладчикам на конференциях различного ранга; в-четвертых, выступления студентов на семинарах по теории межкультурной коммуникации, а также их высказывания по обсуждаемой проблематике в процессе промежуточного и итогового контроля по соответствующему предмету.

Столь очевидно разнородный материал имеет в предлагаемом контексте то преимущество, что предоставляет исследователю уникальную возможность посмотреть на себя в специфическое зеркало, т. е. понять, как «откладываются» в голове у обучающихся обсуждаемые закономерности. Другими словами, предлагаемым путем можно получить доступ к обратной связи особого рода и в итоге осмыслить степень адекватности и продуктивности не только теоретически обосновываемых объяснений наиболее значимых закономерностей межкультурной коммуникации как феномена, но и способов сообщения теоретических сведений, а также способов иллюстрирования изучаемых явлений и сопутствующих им рассуждений.

Частично по этой причине анализ обсуждаемых вопросов не сопровождается привычной отсылкой к источнику. Другим основанием для принимаемого решения является общеизвестность соответствующих «тезисов» в научной и академической среде.

\section{Какие тезисы потенциально способны ввести в заблуждение даже опытных исследователей?}

Из всего массива интересных в обозначенном контексте высказываний целесообразно отобрать лишь несколько, а именно только те, которые из-за своей внешней «правильности» предстают особенно для неподготовленного слушателя как истина и даже как аксиома и гуманистическая и благородная установка, которой требуется обязательно следовать и на словах, и на деле. Кроме того, эти высказывания наиболее часто встречаются не только в студенческой аудитории, но и на научных конференциях. Несмотря на кажущуюся правомочность обсуждаемых тезисов, они либо внутренне противоречивы, либо базируются на ложных посылках, либо при их формулировании не учитываются различия между формой, содержанием и функцией, либо не принимаются во внимание ряд релевантных для их осмысления параметров, т. е. по своей сути обсуждаемые тезисы некорректны. Тем самым необходимо прояснить, что при осмыслении соответствующих умозаключений приводит к нарушению причинно-следственных отношений и в результате - к ложным постулатам, восприятие которых в качестве основополагающих может привести к разрушению концепции в целом.

Поскольку приводимые рассуждения основываются на позиции, уже изложенной с большей или меньшей степенью детализации отдельных положений в некоторых публикациях [6-9], не целесообразно повторять развернутую аргументацию защищаемой точки зрения, однако есть смысл акцентировать ряд мыслей особо. Для этого приводятся в виде цитат 12 высказываний в той форме, в которой их запоминают студенты и активно воспроизводят их на семинарах, ни в малейшей мере не ставя под сомнение истинность цитируемых ими суждений. Все 12 высказываний снабжаются вынужденно лаконичным комментарием, призванным, тем не менее, раскрыть внутреннюю противоречивость цитируемого тезиса или воспроизвести все звенья причинно-следственной цепочки, согласующейся с сущностью рассматриваемого явления и учитывающей диалектику универсального и специфического, общего и частно- 
го, закономерного и случайного, содержания и формы, функции и среды бытования изучаемого феномена.

Итак, теперь собственно разбор ряда широко известных тезисов.

\section{1. «Межкультурная коммуникация - это диалог культур»}

Приведенное высказывание - одно из самых первых утверждений и самая первая и воспринимаемая в качестве основополагающей квази-аксиома, с которыми знакомятся начинающие изучать межкультурную коммуникацию и которую так охотно используют исследователи, давно и прочно зарекомендовавшие себя в той или иной научной области. Многие из последних, конечно же, знают, что они имеют дело с позитивно коннотированной метафорой, активизирующей сведения о взаимодействии людей и о требованиях поощрять диалог в целях установления взаимопонимания между народами. Однако первых упомянутые позитивные коннотации быстро и надолго вводят в заблуждение и не позволяют по-настоящему осознать, что в диалог вступают люди, что взаимопонимание достигается между людьми, что культуры не могут взаимодействовать по определению.

Поэтому и корректный тезис о том, что межкультурная коммуникация - это межличностная коммуникация и что именно данный признак является для межкультурной коммуникации сущностным, начинающие изучать особенности межкультурной коммуникации усваивают с превеликим трудом. Особо трудно им дается понимание того, что межкультурная коммуникация в силу своей сущности - межличностного взаимодействия - всегда имеет потенциально две альтернативы - позитивный и негативный коммуникативный результат. Поэтому одной из задач теории межкультурной коммуникации является изучение условий, способствующих и/или препятствующих благоприятному развитию межличностного взаимодействия (см. подробнее, например, [10]). Между тем такую постановку вопроса, к сожалению, редко встретишь и в специальной литературе (ср., например, публикации $[11 ; 12]$, в которых содержатся такие ответы на проблемные задания, как будто бы предлагаемые ситуации жестко и каузально привязаны только и исключительно к приводимым интерпретациям, с работой [13], где, по сути, анализируются разные интерпретации одной и той же разбираемой ситуации и причины подобного положения дел).

Очевидно, что необходимо иметь в виду и настоятельно подчеркивать, что в силу личностных особенностей коммуникантов интеракция между носителями разных культур может завершиться продуктивно даже при объективно неблагоприятных условиях и, наоборот, конфликтно даже при объектив- но благоприятных коммуникативных условиях. Поэтому начинающим исследователям требуется сразу же усвоить, что успех или неуспех межкультурного взаимодействия - явление нелинейное и подпадает под влияние многочисленных разнородных и порой разнонаправленных факторов. Это, несомненно, требует специального изучения и осмысления (ср. в этой связи постановку задач теории межкультурной коммуникации, а также признание необходимости изучения как позитивного, так и негативного коммуникативного результата, в [6, с. 8, 10-12, 475-482; 7 , с. $10-16,285-308,308-322 ; 8 ; 9])$.

\section{2. «В межкультурной коммуникации все совсем иначе»}

В этой связи можно заметить следующее: все именно так, однако и не совсем так, и даже совсем не так.

Дело в том, что осмыслить приведенное утверждение можно, принимая во внимание два крайних суждения: в межкультурной коммуникации все по-другому - в межкультурной коммуникации все так, как в «своей» культуре.

И для одного, и для другого умозаключения есть основания. В самом деле, в любой культуре сведения о мире кодируются вербальным и невербальными способами, носители культуры проходят социализацию, становясь в конечном итоге культурным типом и оставаясь им на всем протяжении своей жизни. Во всех культурах ее носители вступают в интеракцию, решая разными способами различные когнитивные и коммуникативные задачи. Каждый из носителей культуры обладает одновременно качествами, присущими некоторому психотипу и социотипу. Каждый из носителей культуры имеет и личностную, и коллективную идентичность, а также картину мира, в которой обязательно наличествуют гетерогенные, гетерохронные, гетеросубстратные знания, разделяемые всеми носителями соответствующей культуры.

По этой причине в каждой культуре присутствует и то, что правомерно признать универсальным, а также то, что характеризуется как культурная специфика. Следовательно, принципиально важно корректно разводить явление и его проявление в той или иной культурной среде, разграничивать интегральные и дифференциальные признаки того или иного феномена, усматривать сущность изучаемого явления и проявления сущности под воздействием разнородных факторов. Важно, следовательно, научить носителей одной культуры распознавать и адекватно интерпретировать разнородные маркеры культурной идентичности, определять семиотические границы разной природы, выявлять значимость культурно-специфических сведений согласно инокультурным представлениям - словом, сформировать культурную сенси- 
тивность (чувствительность), что, как правило, в рассуждениях о межкультурной коммуникации, увы, нередко выносится за скобки.

Соотношение универсального и культурно-специфического - величина не постоянная и зависит в том числе от части культуры (материальной, духовной, интеракциональной), которую имеют в виду при анализе, от типа субкультуры, в которую социализированы интерактанты и в которой имеет место анализируемое взаимодействие, от типа реализуемой в актуальных условиях интеракции, а также от единицы анализа (артефакт, ценностная ориентация, интеракция), являющейся предметом изучения в том или ином исследовании. Необходимо учитывать обозначенные параметры, обусловленные тем, что «судьба» артефактов, ценностных ориентаций, организации интеракции, субъекта познания и коммуникации в межкультурной коммуникации и в культуре вообще принципиально не тождественны (см. подробнее рассуждения [14]). Так, максимально признаки культурной специфики проявляются в интеракциональной части культуры, особенно в бытовой коммуникации в интеракциональной части культуры, а минимальные - в высокой культуре (см. данные экспериментального исследования и аргументацию сформулированных обобщений в [10, с. 341-364, 365-383]).

Таким образом, при определении того, насколько культурно-специфичным следует признать то или иное явление, необходимо определиться с тем, что именно является предметом анализа, каким образом и через изучение какой минимальной единицы можно выявить соотношение универсального и культурно-специфического, общего и частного, окказионального и конвенционального.

\section{3. «Носители разных культур имеют разное мировосприятие»}

На первый взгляд к данному умозаключению трудно высказать какие-либо претензии, особенно, если интерпретировать мировосприятие как мировоззрение. Между тем если понимать мировосприятие как восприятие (перцепцию) сведений о культуре, то сразу же возникают разнообразные вопросы.

Первый из потенциально возможных вопросов связан по понятным причинам с феноменологическими свойствами восприятия как явления: субъективностью, аффективностью, селективностью, телеологичностью, контекстной обусловленностью, которые присущи всем видам восприятия (визуальному, аудиальному, одорическому, тактильному, густическому, если называть только каналы восприятия) (см. подробнее, например, в [15]). Очевидно, что упомянутые закономерности являются общечеловеческими, хотя и проявляются они в зависимости от ряда факторов, в том числе и от особенностей субъекта восприятия (ср. характеристику восприятия «субъективность»).

Второй комплекс вопросов обусловлен тем, что нет человека вообще, что каждый человек представляет собой некий вариант культурного типа, является носителем конкретного языка и конкретной культуры, в которой он социализирован. Поэтому, рассуждая об особенностях восприятия сведений о мире, следует также принять во внимание то обстоятельство, что в каждой языковой культуре складываются свои когнитивные стратегии обработки воспринимаемых сведений. По этой причине носители соответствующей культуры научаются первично обрабатывать одни признаки воспринимаемого объекта и абстрагироваться в конкретном акте восприятия от других, определять соотношение когнитивной фигуры и когнитивного фона, усваивают принципы конфигурирования воспринимаемых признаков объектов, их категоризации и концептуализации. Об этом свидетельствуют культурно специфические различия в прототипах ментальных категорий, а также в паттернах действий, как они сложились в определенной языковой культуре (см. подробнее, например, [1620]).

Третий блок вопросов вызван тем, что субъект восприятия является обладателем как уникальных, сугубо индивидуальных, характеристик, так и качеств, общих для определенной социальной группы, к которой он принадлежит, и культуры в целом.

Поэтому цитируемый тезис 3 нуждается в серьезной правке с учетом диалектики универсального и специфического, общего и частного, окказионального и конвенционального применительно к каждой из характеристик восприятия как феномена, к виду восприятия, объекту восприятия, условиям, в которых имеет место восприятие, а также к целям интеракции.

Особого внимания заслуживает четвертый блок вопросов как причинно связанный с особенностями межкультурной коммуникации. Все перечисленные обстоятельства условно можно объединить под «шапкой» «соотношение внешнего и внутреннего аспекта элемента культуры». С помощью названных гносеологических инструментов можно непротиворечиво объяснить, почему носители разных культур, воспринимая в реальности одно и то же, приписывают этому принципиально разное содержание и придают разную значимость. Например, запах лимона в европейском культурном пространстве активизирует у носителей культуры приятные ассоциации, а у носителей юго-восточной Азии - негативные. Престижными признаются в разных культурах разные артефакты, разные профессии, разный образ жизни, причем в разные эпохи соответствующие представления оказываются в одной культуре нетождественными. Практика показывает, что чаще всего значи- 
мость соотношения «внешний аспект - внутренний аспект» недооценивается (см. подробнее [10, с. 351 и далее]). В результате значимость того, что универсально, преуменьшается, а значимость культурной специфики преувеличивается.

Еще одним фактором, существенно обусловливающим не только восприятие сведений внеязыковой действительности, но и их ментальную обработку, являются когнитивные фильтры, когнитивные рамки восприятия, наиболее значимые из которых - рамки «свой - другой», «свой - чужой» (см. подробнее [21; а также 7, с. 117-152]). Комплексы сведений, селектируемых соответствующими когнитивными фильтрами, различаются в количественном и качественном отношении, поскольку прототипическая семантика фильтров «свой», «чужой», «другой» не тождественна. В итоге влияние названных фильтров на селекцию сведений, подлежащих затем детальной и глубокой ментальной обработке, существенно обусловливает результат категоризации и концептуализации воспринимаемых сведений и в конечном счете - выбор номинативных средств для обозначения ситуации и ее элементов.

Такие же соображения важно принимать во внимание при анализе барьеров в межкультурной коммуникации, которые также тесно связаны с процессами мировосприятия. И здесь также есть свои закономерности: интегральные и дифференциальные признаки актуальных коммуникативных событий воспринимаются по-разному: первые не позволяют коммуникантам видеть значимые для разных культур различия, вторые не воспринимаются как коммуникативно и когнитивно значимые [10, с. 381 и далее].

\section{4. «В разных культурах картина мира разная,}

потому что, например, у русских есть синий и голубой цввет, а у немцев/англичан только синий»

Процитированный тезис 4 можно с полным правом отнести к расхожим формулировкам, принятым и регулярно воспроизводимым не только в теории межкультурной коммуникации, но и в других науках, в том числе и в лингвистике. Различаются соответствующие высказывания только примерами, из которых наиболее часто встречаются обозначения в разных языках частей человеческого тела (рук, ног, пальцев) или цветообозначения.

Однако если вдуматься, то это квази-аргументы, поскольку сравнивается одно, имеется в виду другое, исследуется третье. В самом деле: в описанных случаях сопоставляются отдельные языковые средства как единицы лексикона, т. е. как номинативные единицы, изолированные от коммуникативных условий и зафиксированные как элементы лексической системы. Подразумевается же анализ структуры картины мира в целом, т. е. структура и принципы организации отношений между комплексами сведений о мире, значимых для носителей конкретной культуры. Вывод же делается об особенностях восприятия мира носителями культуры и о специфике категоризации и концептуализации уже ментально обработанных сведений, присущих не конкретному субъекту познания и коммуникации, а коллективному субъекту.

Другими словами, сравниваются несравнимые явления - обозначения отдельных элементов внеязыковой действительности, с одной стороны, и использование/функционирование языковых средств в разных интеракциях при решении коммуникантами разных коммуникативных и когнитивных задач как средств реализации когнитивных, номинативных и коммуникативных стратегий - с другой. Следовательно, имеют место когнитивные стратегии, с одной стороны, и номинативные средства реализации когнитивных стратегий - с другой; коммуникативные стратегии для решения некоторой когнитивной и коммуникативной стратегии, с одной стороны, и выбор одного из изофункциональных средств и способов реализации соответствующей задачи - с другой. Фактически налицо - отождествление референта и обозначения, одного из многих способов решения номинативной задачи с комплексом сведений о номинируемом объекте. Это, очевидно, некорректно и непродуктивно, поскольку заводит соответствующие рассуждения в тупик, а начинающих исследователей вводит в заблуждение из-за смешения терминов и отсутствия разграничения сущности и ее проявлений, обозначения и его референта.

Кроме того, к сожалению, не усматривают разницы между статическим взглядом на номинацию познанных элементов действительности и динамическим взглядом на функционирование языковых средств в коммуникации. И даже если поэлементные обозначения могут в разных культурах не совпадать, то это отнюдь не означает, что в реальной коммуникации неспецифическими (вторичными и/или метафорическими, а также синонимическими, антонимическими, фразеологическими и другими средствами) не могут активироваться и со-активироваться сведения, позволяющие коммуникантам понять, имеются ли в виду пальцы рук или ног, какой именно цвет у именуемых объектов (хотя в языке могут отсутствовать специализированные обозначения), ср.: встать на пальцьь - взять в пальцыь; синий, как утреннее небо; синий, как бушующее море.

Следовательно, при анализе языковой картины мира важно последовательно разграничивать, с одной стороны, комплексы сведений по определению культурно-специфической внеязыковой действительности, организованные тем или иным образом, и средства обозначения этих комплексов сведений, с другой стороны. Последние разнородны и разно- 
образны, поскольку в культуре имеются многочисленные способы активизировать набор соответствующих сведений. Об этом убедительно свидетельствуют, например, особенности семантической и синтаксической микро- и макроорганизации текста, к примеру, структура номинативной цепочки как комплекса обозначений одного и того же референта в тексте, выявляемая на основании тождества референта. Таким образом в коммуникацию вводятся все новые сведения об одном и том же референте, обогащая представления о действительности реципиента текста.

Вместе с тем вряд ли целесообразно ставить под сомнение сам тезис о культурной специфичности картины мира, понимая под последней структуру всего комплекса разнородных связей между признаками, значимыми для активизации того или иного понятия в определенной культуре.

В таком контексте особо значимыми представляются обобщения Фр. Кликса, который серией экспериментов выявил у многоместных глаголов латентную со-активацию отношений их аргументов с другими аргументами [20, S. 14]. Поэтому отношение у $S I E G E N /$ пбеждать с другими понятиями интерпретируется как трехместное, а именно $x R 1,2,3$ (yzu) в силу имеющихся связей с тремя понятиями (а не с языковыми средствами!): SIEGEN (KÄMPFEN, BESIEGEN, GEGNER)/побеждать (бороться, одерживать победу, противник) [Ibid., S. 14]. Фр. Кликс приходит к заключению, что понятия в памяти кодируются через их признаки, т. е. кодирование фиксирует не понятия как таковые, а определенный тип отношений между понятиями [Ibid., S. 15]. По этой причине правомерно говорить о том, что в памяти складываются понятийные конфигурации, сводимые затем к образованиям более высокого уровня абстракции [Ibid., S. 69], и использование слова одномоментно активирует весь набор признаков, соотносимый в памяти с тем или иным понятием (cp. [Ibid., S. 69 и далее]).

В силу сказанного очевидно, что в картине мира могут присутствовать как культурно-специфические, так и универсально значимые признаки того или иного понятия, однако вся конфигурация отношений между комплексами сведений в картине мира не может не быть культурно-специфичной. Ср., сколь различен набор признаков, мотивирующих обозначение одного и того же растения в разных языковых культурах подснежник/Schneeglöckchen - в одном случае, очевидно, цвет, место произрастания, в другом - цвет, форма, размер. Еще одним примером в поддержку сказанному могут послужить и конвенциональные для определенных категорий коммуникантов формулы приветствия: Привет! / How do you do! или же семантика улыбки при взаимодействии незнакомых коммуникантов друг с другом в разных культурах.
Иллюстрацией к сказанному могут быть также обозначения одного и того же элемента природного ландшафта, принятые в разных культурах: Английский канал-Ла-Мани, Бискайский залив-Кантабрийское море, Восточное море - Балтийское море, ЭверестДжомолунгма и т. п., различные конфигурации родственных отношений со специфическими обозначениями родственников и родственных связей, семантическая структура лексемы с количественными и качественными различиями у семантических множителей, прототипы ментальных категорий, функциональная сфера концептуальных метафор, структура грамматических категорий в генетически родственных языках и пр.

Вряд ли высокой объяснительной силой относительно специфики и структуры картины мира обладают также данные о количестве синонимичных и/ или изофункциональных средств для обозначения того или иного референта либо средств выражения грамматической и/или функционально-семантической категорий, рассматриваемых под статическим углом зрения в арифметическом ключе.

В том числе и по изложенным выше соображениям предположения о существовании в картине мира только нескольких культурно-специфических (или лингвокультурных, культурных) концептов с трудом сможет выдержать критику. Данная гипотеза, по всей видимости, по умолчанию базируется на представлении о наличии в картине мира универсальных концептов, на фоне которых исследователи способны выявить так называемые культурные концепты. Однако подобная формулировка некорректна по своей сути, так как все знания носители языка и культуры получают из культуры, т. е. из вторичной среды своего бытования, причем культура и принятые в ней ее носителями образцы обработки воспринимаемых сведений, естественно, обусловливают рецепцию и интерпретацию сведений и о первичной среде - природной.

В обсуждаемом контексте необходимо также вспомнить и аргументы относительно «культурно-специфических различий мировосприятия» (см. выше).

\section{5. «В процессе межкультурной коммуникациии} люди приобретают новую идентичность»

Цитируемый тезис 5 можно, пожалуй, внести в рубрику общепринятых и аксиоматичных, особенно тогда, когда в качестве исходного принимается положение о доминировании культурной специфики в любом культурном пространстве. Между тем еще Р. Познер, рассуждая с общесемиологических позиций о способах бытования артефактов, ментефактов и субъектах в инокультурном пространстве, отмечал принципиальные различия между ними. Так, инди- 
виды могут стать членами другого общества и привнести в него свои артефакты, идеи и ценности. Артефакты могут быть использованными, заимствованными или скопированными членами другого общества, не влияя при этом на социальные отношения между членами общества. Ментефакты, определяя поведение индивидов в обществе, могут восприниматься членами другого общества и предопределять их поведение [14, S. 49].

Если признать, что идентичность представляет собой результат социопсихологического эмоционально-рационального когнитивного процесса, протекающего в конкретном социокультурном контексте и в определенных коммуникативных условиях при (сознательной) рефлексии, то необходимо осознавать, что соответствующий процесс, осуществляемый субъектом идентичности в любом акте познания и коммуникации, является когнитивно-деятельностным феноменом, основа которого - когнитивная и коммуникативная деятельность как единичных, так и коллективных субъектов в любых условиях разнообразных интеракций [21]. Ментальная структура идентичности объединяет в себе не только гетерогенные, гетеросубстратные, гетероструктурные сугубо индивидуальные знания, совокупность которых можно описывать как личностную идентичность носителя языка и культуры, но и знания, разделяемые всеми носителями соответствующей культуры, складывающиеся в структуры коллективной идентичности единичного субъекта [21].

Если также принять во внимание, что новое знание, получаемое субъектом познания и коммуникации, т. е. носителем коллективной и личностной идентичности, встраивается в уже имеющиеся у субъекта структуры знания (см. подробнее [22, S. 122 и далее; 23, с. 116-119, 146-151]), то станет очевидно, что утверждения типа приведенных выше (см. тезис 5) лишены основания.

Другими словами, в процессе аккультурации, т. е. вторичной социализации в инокультурное пространство, субъект встраивает приобретаемое им в новых социокультурных условиях новое знание в имеющиеся у него ментальные структуры. Последние получают поэтому дифференциацию имеющегося у них комплекса сведений о мире по еще одному параметру - особенности культурной среды (ср. схему 3.3 в [23, c. 118]). Таким образом, понятно, что соответствующие структуры, дифференцируемые дополнительно и более тонко, так и остаются частью ментальной структуры личностной и коллективной идентичности. Поэтому, думается, разные люди с межкультурным опытом оценивают для себя последний как несомненное обогащение (см. подробнее [10]).

По изложенным причинам концепции «скользящей идентичности», «креолизованной идентичности» и им подобные трудно признать в качестве обладающих объяснительной силой. Человек с межкультурным опытом имеет одну, единственную, личностную и коллективную идентичность, в ментальной структуре которой комплексы разнородных сведений дифференцированы в том числе по параметрам «культурная среда». Идентичность способна к разнообразному трансформированию как в «своей», так и в «чужой» культурной среде (но не к умножению или к количественному увеличению!). Благодаря этому носители культуры способны различать не только интегральные признаки интеракции и отличать приветствие от прощания, благодарность от претензии, но и имеют четкие сведения о количественных и качественных отличиях организации одного типа интеракции в разных культурах, т. е. знают, как приветствовать в официальной и неофициальной обстановке в тех культурах, в которых они прошли и первичную, и вторичную социализацию.

В некоторых исследованиях можно встретить высказывания типа «люди с общим социальным опытом», которые отдельные исследователи предпочитают использовать вместо термина «идентичность». Думается, что процитированное высказывание ни в коей мере не ставит под сомнение высокую объяснительную силу категории «идентичность», а лишь называет основание для формирования идентичности, т. е., по сути, акцентирует социокультурный характер процесса формирования личностной и коллективной идентичности носителей языка и культуры и тем самым значимость для продуктивного взаимодействия коллективной идентичности и конвенциональных средств решения коммуникативных и когнитивных задач.

\section{6. «Невербально закодированная информация} в коммуникации более значима, так как количество невербальных кодов существенно превылиет количество вербальных»

Если быть честным, то термину «код» по-настоящему «не везет», поскольку в публичном пространстве к этому термину прибегают едва ли не в каждом случае, когда речь заходит о способах фиксации некоторого комплекса информации: «Это разрушает русский культурньй код», «Это противоречит наиему цзивилизационному коду» и пр. Поспорить с термином «код» по нетерминологическому употреблению в публицистике, политике и медиапространстве - даже в научной коммуникации - может разве только лексема шок, ср. наиболее часто встречающееся: «Я испьтал (подлинный) культурный шок!» (увидев в магазине 20 сортов сыра / узнав о традициях в инокультурном пространстве / ознакомившись с необходимостью соблюдать определенные правила, не приятые в «своей» культуре / выяснив принятое в «чужой» культуре значение привычного для комму- 
никанта действия / осмыслив ценностные ориентации своего инокультурного окружения...).

Нетерминологическое употребление научного понятия в несвойственной для него среде - лишь одно из потенциальных объяснений упомянутого положения дел. Но к сожалению, все гораздо сложнее, глубже и тоньше. Дело в необходимости изучения того, как соотносится вербальный код с невербальными культурными кодами в интеракции того или иного типа, а также в определении четких и надежных критериев разграничения элементов некоторого культурного кода от прочих средств и способов фиксации сведений о мире, средств и способов объективации этих сведений. Это, очевидно, не является тождественным таким процессам, как активизация, со-активация, вербализация сведений о мире.

Дело в том, что первая из названных выше исследовательских задач осмысляется преимущественно вне учета средств и способов кодирования сведений о мире в интеракции конкретного типа, вне соотнесения этих средств с характером реализуемой коммуникативной стратегии и категорий коммуникантов. Вторая из упомянутых исследовательских задач, по сути, уравнивает значимость всех средств и способов фиксации, объективации и со-активации воспринимаемых коммуникантами в коммуникации сведений о мире, не принимая во внимание, что не все воспринимаемые субъектами познания и коммуникации сведения значимы для осуществления конкретной интеракции (ср. только такие свойства восприятия, как селективность и телеологичность).

Вопрос о соотношении вербального кода и невербальных кодов, несомненно, весьма важная область исследования. Однако теоретическая значимость проблематики не означает отказа от вдумчивого осмысления тех или иных расхожих утверждений, которые тиражируются, к сожалению, без их критического анализа.

Причина данного обстоятельства, думается, заключается, во-первых, в том, что в подобных случаях действует, как свидетельствует анализ соответствующих рассуждений, арифметический подсчет культурных кодов как таковых, а не учет средств реализации определенной коммуникативной стратегии в известных коммуникативных условиях коммуникантами с определяемыми психосоциальными, социокультурными, когнитивными и прочими особенностями личностной и коллективной идентичности. Не принимается, как правило, во внимание, что, хотя в интеракции синхронно задействованы практически все культурные коды, не все из них представляют в конкретных коммуникативных условиях коммуникативную и когнитивную ценность. Например, цвет волос, их структура и степень ухоженности, прическа и другие параметры способны транслировать в прин- ципе важные индивидуально-физиологические и социокультурные сведения о личности коммуниканта. Однако для организации интеракции «лекция» и для ее успешности эти сведения, очевидно, совершенно не значимы, и поэтому не учитываются ни лектором, ни слушателями. В противном случае существовали бы определенные правила касательно прически, чтобы допускать слушателей на лекции по тому или иному предмету.

Во-вторых, ни в теоретическом, ни в прикладном смысле не разграничиваются два абсолютно нетождественных явления: фиксация сведений о культуре и внеязыковой действительности, с одной стороны, и культурные коды - с другой. Между тем данная задача чрезвычайно важна, так как сведения из одной и той же ментальной структуры могут активироваться и со-активироваться не только разнородными вербальными средствами (лексико-семантическими, словообразовательными, морфологическими, синтаксическими, стилистическими, формально-структурными), но и средствами невербальных кодов (оптики, акустики, одорики, гаптики, густики, проксемики, жестики, мимики, хронемики и др.).

В-третьих, вербально кодируется, активируется и со-активируется информация, всегда когнитивно и коммуникативно значимая в актуальной интеракции. И это обстоятельство не может быть ни при каких случаях отменено, даже если арифметически средства вербального кода существенно уступают в количественном отношении средствам невербальных кодов. Последние поэтому вряд ли можно признать в принципе равноценными вербальным, хотя, конечно же, в отдельных случаях невербальные средства оказываются весьма релевантными в том или ином акте познания и коммуникации. Их вклад в общий итог взаимодействий заключается главным образом в модификации комплекса активируемых и со-активированных сведений, в изменении соотношения когнитивной фигуры и когнитивного фона, в перспективизации и/или (пере)акцентуации тех или иных сведений.

В-четвертых, вербальные средства могут именовать не только разнородную и разнообразную конкретику, но и абстрактные сущности разной природы и разной степени абстракции, причем не только элементы реальной действительности, но и элементы виртуальной действительности и любого из возможных миров. Невербальные средства, как правило, активизируют весьма конкретные сведения и в конкретных условиях.

Кроме того, процитированное утверждение 6 практически лишается смысла, если не сообщается методика подсчетов соотношения вербального и невербального в коммуникации, т. е. в динамике, или даже в статике, а значит при анализе способов объ- 
ективации сведений о мире в культуре вне конкретного акта познания и коммуникации. Так и хочется спросить: кто и как считал, заявляя, что «невербально закодированная информация составляет 70-75 \% от объективируемых сведений»?

\section{7. «Язык - это идентичность, разные языки - разные идентичности»}

На первый взгляд данное утверждение не противоречит пониманию того, что носители конкретного языка и конкретной культуры имеют разную идентичность. Между тем данное утверждение не совсем корректно, поскольку связь языка и идентичности носителя культуры проявляется не в особой структуре языка или лексикона, а в том, как носитель конкретной культуры использует разноуровневые и разнородные средства языка: лексико-семантические, морфологические, синтаксические, словообразовательные, текстограмматические, формально-структурные, стилистические - для решения некоторой коммуникативной и когнитивной задачи. С этой точки зрения значение имеет, как он, носитель языка и культуры, структурирует в конкретных коммуникативных условиях информационный поток, какие сведения о мире, воспринимаемые в актуальном акте познания и коммуникации, он эксплицирует, а какие имплицирует, какие вербализует с высокой степенью дифференциации, а какие объективирует максимально общо. В данном контексте внимание заслуживает, насколько равноправными в коммуникации носитель языка и культуры признает вербальные и невербальные средства овнешнения сведений о мире, насколько активно в коммуникации задействуются невербальные средства и какие именно.

Однако разобрать, в чем суть дискуссии, в данном случае довольно сложно, поскольку в гуманитарных науках сложилась давняя традиция в понимании соотношения языка и идентичности личности, традиция, которая довлеет над исследователями при осмыслении соответствующей проблематики. Но изучение закономерностей функционирования языка и описание его гетерогенных средств убеждает в том, что не сам язык дает представление об идентичности, а особенности его употребления [21]. И дело не в большей или меньшей степени точности формулируемой мысли, т. е. не в редактуре, а в понимании сущности языка как культурного кода, как средства познания и коммуникации. В самом деле, имеются разные варианты английского языка, разные варианты французского, немецкого, испанского и т. д. И разнообразные и разнородные средства этих языков реализуют в разных культурных пространствах нетождественным образом функционал языка. Это выражается в том числе в особенностях содержательной, формальной, функциональной организации текста на микро- и макроуровне, что можно описать как варьирование текста в коммуникации [24].

\section{8. «Язык-способ существования культуры»}

Неправомерность процитированного тезиса 8 не очевидна прежде всего студентам из-за того, что они на занятиях по теории межкультурной коммуникации многократно слышат о наличии в любой культуре различных способов фиксации разнородных сведений о культуре, среди которых языковые средства занимают особое место в силу особенностей языка как средства познания и коммуникации.

Однако при всей особой функциональной нагруженности языка как культурного кода ясно, что разнородные сведения о культуре кодируются не только языковыми средствами, но и многочисленными невербальными средствами. Последние - это не только средства невербальных культурных кодов (оптики, акустики, густики, одорики, гаптики, мимики, жестики, проксемики, хронемики и др.), но и артефакты как «овеществленное поведение» (Л. Уайт), стереотипы сознания, образы мира, доместикаты, разнообразные преобразования природной среды, семиотические системы типа космогонических и/или эсхатологических мифов, символы, архетипы и пр.

Материальные следы давно исчезнувших цивилизаций и культур показывают, что более или менее четкие представления о культурных особенностях можно получить и без данных, фиксируемых языковыми средствами. Именно поэтому процитированное в тезисе 8 утверждение является явной натяжкой, преувеличением, сделанным с очевидными «добрыми» намерениями, приводящими, как известно, в ад. И хотя автор высказывания 8 и стремился акцентировать особые функции языка как культурного кода, он вводит начинающих исследователей в заблуждение, т. е. оказывает им медвежью услугу.

\section{9. «Язык-фактор формирования культурных кодов»}

Чтобы понять абсурдность соответствующего утверждения, достаточно вспомнить, что фактор это обстоятельство, так или иначе обусловливающее функционирование некоторого явления или объекта. Отсюда ясно, что культурные коды никак не могут формироваться под воздействием языка. Кроме того, сам язык является культурным кодом, и внутри него может формироваться только так или иначе организованная подсистема вторичных средств, призванных кодировать, активизировать и со-активировать некоторые сведения о мире. Более того, разнородные языковые средства, сформировавшие культурный код как комплекс средств, способных к дифференцированной фиксации и трансляции разнородных сведений о внеязыковой действительности, как правило, 
не используются вне других видов, типов, аспектов деятельности, которую выполняет человек как носитель языка в определенных условиях. Другими словами, человек использует языковые средства не ради использования этих средств, а для достижения некоторой внеязыковой цели, реализуя некоторую коммуникативную стратегию: построить дом, написать книгу, объяснить сыну решение математической задачи, связать носки, постирать платье, сварить обед, пригласить друзей на чай и пр. Каждая из интеракций осуществляется с помощью специфических вербальных и невербальных средств. И данное обстоятельство само по себе не может объяснить, под влиянием каких факторов формируются культурные коды.

Между тем необходимость так или иначе ответить на скрытый в процитированном тезисе вопрос требует изучить, какие именно условия благоприятствуют или препятствуют формированию культурных кодов. Важно также уяснить, почему многочисленные средства фиксации культурно-специфического знания так и не образуют культурного кода. Интерес представляет и поиск ответа на вопрос, почему в разных культурных пространствах одни и те же элементы нагружены семиотически по-разному. И конечно же, факторы, обусловливающие формирование культурных кодов, бесспорно, должны быть исчислены, детально описаны не только в пределах внутрикультурной, но и при межкультурной коммуникации в разных культурных пространствах.

\section{0. «Если преодолеть стереотипы, то не будет} конфликтов в межкультурной коммуникаичии»

Все те, кто некритически воспроизводит тезис 10 , даже не задумываются над тем, что стереотипы являются неотьемлемой частью нашего сознания, которое произвольно - даже продуманными, систематическими и системными воспитательными мерами - вряд ли можно искоренить. Ведь на место «искорененных» стереотипов неизбежно встанут другие, не менее устойчивые и «живучие».

Не задумываются «искоренители» стереотипов также над тем, что стереотипы, будучи гипергенерализованными, конвенционализированными, ригидными суждениями о том или ином объекте и/или субъекте, событии и т. п., актуальными в конкретном культурном пространстве, представляют собой по своей природе образцы осмысления воспринимаемых сведений. В силу этого они являются для носителей культуры надежными когнитивными инструментами для рецепции в актуальных актах взаимодействия и для формирования реакции на воспринимаемое, т. е. для выбора способов и средств взаимодействия здесь и сейчас (см. подробнее [6; 7, с. 153-201]). Поэтому стереотипы, с одной стороны, помогают быстро и эффективно обрабатывать воспринимаемые сведения, хотя, с другой стороны, прогнозируемо провоцируют многочисленные аберрации при концептуализации сведений, воспринимаемых в межкультурной коммуникации. Причина подобных аберраций в том, что в каждой культуре специфичны и прототипы ментальных категорий, и паттерны взаимодействия между коммуникантами, а также в том, что носитель определенной культуры не владеет прототипами и паттернами обработки сведений о мире, релевантными в другой.

В силу этого очевидно, что в действительности сторонники критикуемой точки зрения только препятствуют достижению прокламируемой благородной цели, т. е., по сути, множат препятствия для адекватного осмысления сущности межкультурной коммуникации.

\section{1. «Этноиентризм требуется последовательно изживать»}

Высказанные уже соображения убеждают в том, что этноцентризм целесообразно воспринимать в научном исследовании как неизбежное зло, если уж рассуждать в терминах «польза - вред». Неизбежность этноцентризма обусловлена первичной социализацией в культуру, в силу чего то, что субъекту познания и культуре предлагает его культура, представляется ему естественным, само собой разумеющимся порядком, безальтернативной реальностью, нормальной нормальностью. У носителя языка и культуры нарабатываются способы осмысления воспринимаемых сведений, способы взаимодействия с другими носителями культуры и принципы варьирования этими способами в зависимости от разнородных и разнообразных факторов как наборы когнитивных, номинативных и коммуникативных стратегий вкупе со средствами их реализации. Поэтому, не обладая в инокультурной среде аналогичным когнитивным и коммуникативным опытом, обеспечивающим адекватную новым условиям обработку воспринимаемых сведений и продуктивное, бесконфликтное взаимодействие, люди испытывают столь значительные сложности, что не справляются с когнитивным диссонансом, вынуждены преодолевать многочисленные барьеры в межкультурной коммуникации и не могут не испытывать культурный шок той или иной степени выраженности.

Поэтому так необходимо показать обучающимся закономерный характер барьеров в межкультурной коммуникации и учить носителей культуры минимизировать соответствующие последствия и оптимизировать взаимодействие представителей разных культур. 
12. «Культурный релятивизм - неадекватный гносеологический инструмент для осмысления межкультурной коммуникации»

Соображения, аналогичные высказанным при обсуждении предыдущего тезиса 11 , справедливы и в данном случае. В качестве примера достаточно напомнить о культурной специфике представлений о, например, красоте, которые к тому же могут существенно меняться в зависимости от особенностей эпохи. Так, сегодня популярность завоевывает так называемый боди-позитивизм. Кроме того, универсальные представления о добре и зле, о хорошей девочке и плохом мальчике, о престижной профессии, о ценности человека, об уюте, об идеальных родителях, об образцовых отношениях родителей и детей, об идеальном обществе и т. п. оказываются наполненными не только культурно-специфическим содержанием, но и подлежат серьезной правке в зависимости, по крайней мере, от поколения носителей культуры и эпохи, которую переживает соответствующая культура. И это при том, что универсальны сами категории «добро», «порядочность», «честность», а также «подлость», «предательство», «зло», которые, стоит повторить, наполняются в разных культурных пространствах разным содержанием.

Таким образом, анализ избранных для детального обсуждения тезисов убедительно показывает, что речь идет не о редактировании не совсем удачных высказываний, а об осмыслении сущности изучаемого явления - межкультурной коммуникации как межличностного взаимодействия носителей разных языков и культур. При этом каждый из коммуникантов обладает специфической личностной и коллективной идентичностью, оставаясь при этом обладателем того или иного психотипа и социотипа, которые у обоих коммуникантов по своим разнородным характеристикам могут как совпадать, так и различаться.

\section{Причины распространения обсуждаемых аберраций}

Размышляя над основаниями распространения проанализированных тезисов, их устойчивости и, даже можно сказать, популярности в научной и академической среде, можно выделить несколько причин, с разной степенью влияющих на осмысление межкультурной коммуникации и постановку исследовательских задач в данной области.

В качестве первой, но пожалуй, не определяющей, стоит назвать небрежное отношение к использованию терминологии, а также нежелание в теоретических рассуждениях последовательно соблюдать конвенциональное для той или иной научной школы и строго научное употребление термина, сложившиеся в науке в целом. Не всегда придается значимость тому, что один и тот же термин может иметь разное содержание в разных науках/концепциях на разных этапах развития соответствующей теории.

Следствием отмеченного обстоятельства становится, например, регулярное обращение к рабочим терминам, которые слушатели/читатели зачастую трактуют не так, как это делает исследователь при подготовке доклада или публикации. Сюда же, по всей видимости, можно отнести и введение авторских трактовок общеупотребительных терминов вместо того, чтобы предлагать новое обозначение для нового содержания. В результате побеждает, естественно, интегральное начало, а дифференциальные признаки в трактовке содержания научного понятия либо вообще забываются, либо трактуются как несущественное дополнение к уже известному.

В это же объяснение вполне вписывается и возможность использования термина в бытовом понимании как в обыденной дискуссии, так и при употреблении той же единицы для обозначения научной категории. Наиболее часто это касается единиц терминосистемы, восходящих к нейтральной лексике, например, культура, картина мира, личность, язык, понятие, ситуация и т. п.

Второй причиной описанного положения дел является то, что зачастую не придается никакой значимости разграничению содержания, формы, функции, сферы функционирования рассматриваемого феномена и факторов, влияющих на реализацию функционала изучаемого явления. Не разграничиваются сущность и ее проявление, не называются и нередко именно вследствие этого не изучаются факторы, обусловливающие функционирование того или иного феномена и реализацию его функционального потенциала. Поэтому слушатели/читатели к своему удивлению могут узнать, что «межкультурная коммуникация не понимается так, как это сделал предыдущиий докладчик» (т. е. как межличностное взаимодействие), «так как изучается звучащуая речь» или «так как используются специфические методики анализа, ещуе не принятые в исследовании обсуждаемого феномена» и пр.

Но наиболее серьезным в обсуждаемом контексте является отождествление сущности и ее проявления, изучаемого объекта и его признаков, признаков, свойственных самому объекту в силу природы последнего, и признаков, выявляемых определенными методами анализа, т. е. онтологических и гносеологических признаков. В результате в фокусе исследования оказываются не сущности, а маркеры, по которым в тех или иных условиях можно опознать явление, например, степень интенсивности жестикуляции вне рассмотрения эмоционального состояния коммуниканта или престижность одежды без учета соотношения личностной и коллективной идентичности инди- 
вида и доминирующих ценностных ориентаций социального класса, к которому принадлежит последний.

Третьей причиной можно назвать неумение или нежелание принять тот непреложный факт, что одна и та же коммуникативная и когнитивная задача имеет не только в разных культурах, но и в одной культуре несколько способов и средств ее решения, например, чтение лекции по тому или иному предмету или разными лекторами на одну тему, либо одним и тем же лектором на одну тему в разные годы преподавания.

К тому же разряду изучаемых причин следует отнести и необходимость четкого понимания того, что, как бы банально это ни звучало, одна функция может иметь несколько способов своей реализации, одно содержание может объективироваться разными формами, а одна форма может иметь разное содержание. При этом не стоит упускать из виду соотношение моно- и полифункциональных средств.

Применительно к изучению межкультурной коммуникации особо значимым оказывается знание о равноправии и/или неравноправии вербальных и невербальных средств при достижении одной цели в некоторой интеракции, а также умение корректно соотносить внешний и внутренний аспект конкретного элемента культуры.

Обобщая, следует особо подчеркнуть особую значимость точности и корректности в использовании научного аппарата и методик анализа при изучении межкультурной коммуникации, потому что всякая поверхностность и недооценка «мелочей» приводит к неадекватному осмыслению изучаемого феномена и как следствие - к пренебрежению тем самым благородными гуманистическими установками, которые пропагандируются в публичном пространстве. Любая приблизительность, опора на «само собой разумеющуееся» приводят к реализации установки: "Два пишем, семь на ум пошло» - и в результате к конфликтам разной степени интенсивности.

\section{Почему обсуждаемые тезисы и стоящие за ними процессы опасны и вредны?}

Анализ отобранных для детального обсуждения тезисов убеждает, что неточное формулирование мыслей не столь безобидно, как это может показаться на первый взгляд.

Опасность их заключается прежде всего в том, что они затемняют суть изучаемых явлений, приучают пренебрегать тонкими различиями, столь значимыми при межкультурном взаимодействии. Ведь улыбка не ко времени, «не тот» поворот головы, «не то» движение руки и пр. могут стать причиной серьезных конфликтов, могут способствовать укорене- нию предрассудков и предубеждений, а также негативных гетеростереотипов, которые и так по своей природе чрезвычайно ригидны.

Вредны процитированные и аналогичные им тезисы потому, что их сейчас задействуют при конструировании симулякров и фейков. Они весьма активно используются также при реализации таких стратегий, как хейтинг, троллинг, булинг, а также при разного рода манипулировании, поскольку их формальная псевдонаучность, явная общеизвестность, легкая запоминаемость создают атмосферу аргументированности излагаемой позиции и не вызывают у реципиента желания вдуматься в суть формулируемых «закономерностей».

Поэтому и в студенческой аудитории при самостоятельном освоении соответствующей проблематики высказывания типа процитированных выше звучат довольно часто и, увы!, без должной критики со стороны студентов, которые не замечают в цитируемых ими рассуждениях подводные камни, не способны определить перебой в логике, не могут усмотреть подмену понятий и некорректность трактовок.

\section{Выводы}

Выводы, как это ни покажется странным, банальны и, увы, предсказуемы.

Первое. Формулируемые обобщения не могут не затронуть обе стороны - как начинающих исследователей межкультурной коммуникации, так и ее опытных исследователей, а также создателей учебных пособий и составителей практикумов и тренингов. Создатели учебников и учебных пособий по межкультурной коммуникации должны быть предельно внимательными к формулировкам и весьма взвешенными в своих суждениях, поскольку их комментарий может быть прочитан начинающими изучать межкультурную коммуникацию не так, как бы первым того хотелось. Начинающие же исследователи нуждаются в критическом мышлении и умении различать сущность и ее проявление, кодирование и декодирование сведений о мире, универсальное и культурно-специфическое, общее и частное, привычное и необычное, закономерное и случайное.

Второе. Необходимо учить студентов корректно мыслить, выстраивать причинно-следственные цепочки, адекватно использовать терминологию, учитывая особенности теоретических основ, на которых строится изучение феномена. Требуется уметь различать сущность изучаемого феномена и определять его признаки и способы выявления функционального потенциала.

Для этого нужно уметь владеть методиками анализа и знать их объяснительную силу и очевидные, но неизбежные, ограничения на те или иные параме- 
тры. Знать, как проникать в сущность изучаемого явления, как различать аналогичные или кажущиеся таковыми явления. Различать конститутивную единицу и минимальную единицу анализа. Требуется учить начинающих исследователей анализировать, сравнивать, классифицировать, обобщать, т. е. учить когнитивным операциям, обеспечивающим успешность когнитивной деятельности. Учить видеть, стоит ли за новым обозначением принципиально новое содержание, или же некто пытается с помощью нового слова повторить уже давно в науке известное и скрыть это хотя бы на первое время. Учить концентрировать свои усилия на изучении явления, а не на воспроизведении заученного. Словом, учить учиться.

Третье. Сказанное убеждает в том, что речь не идет об осмыслении проблематики конкретной теории. Напротив, речь может идти только о формировании стратегий корректного осмысления содержания воспринимаемых текстов, другими словами, о системности подготовки человека, способного к самостоятельному критическому мышлению и к творческой деятельности в избранной ими профессиональной cфepe.

\section{ЛИТЕРАТУРА}

1. Tsvasman L. Manipulation // Das große Lexikon Medien und Kommunikation. Hrsg. von Leo R. Tsvasman. Würzburg : Ergon-Verlag, 2006. S. 226-228.

2. Pugatschjow $V$. [Faktoren und Merkmale der Manipulation] // Das große Lexikon Medien und Kommunikation. Hrsg. von Leo R. Tsvasman. Würzburg : Ergon-Verlag, 2006. S. 228-233.

3. Merten $K$. Macht der Medien [power of the (mass) media] // Das große Lexikon Medien und Kommunikation. Hrsg. von Leo R. Tsvasman. Würzburg : Ergon-Verlag, 2006. S. 224-226.

4. Antos $G$. Fake News. Warum wir auf sie reinfallen. Oder: "Ich mache euch die Welt, so wie sie mir gefällt". Sprachdienst, 2017. Heft 1. S. 1-20.

5. Grischaewa L. I. Homo ludens, Fake News und Text, oder warum ändern sich die Textgestaltungsprinzipien? // Русская германистика : ежегодник Рос. союза германистов. Т. 17: Типология текстов и дискурсивные практики в немецкоязычном культурном пространстве. М. : ФЛИНТА, 2020. С. 24-47.

6. Гришаева Л. И., Цурикова Л. В. Теория межкультурной коммуникации : проблемы, подходы, анализ. Воронеж : Издательский дом Воронеж. гос. ун-та, 2018. $505 \mathrm{c}$.

7. Гришаева Л. И., Цурикова Л. В. Введение в теорию межкультурной коммуникации. Изд. 5-е. М. : Academia, 2008. 352 c.

8. Гришаева Л. И., Цурикова Л. В. Концептуальные основы анализа межличностного взаимодействия носи- телей разных культур (часть 1) // Вестник Воронеж. гос. ун-та. Сер.: Лингвистика и межкультурная коммуникация. 2013. № 1. С. 14-21.

9. Гришаева Л. И., Цурикова Л. В. Концептуальные основы анализа межличностного взаимодействия носителей разных культур (часть 2) // Вестник Воронеж. гос. ун-та. Сер.: Лингвистика и межкультурная коммуникация. 2013. № 2. С. 30-35.

10. Стратегии успеха и факторы риска в межкультурной коммуникации : кол. монография / под ред. Л. И. Гришаевой, Л. В. Цуриковой. Воронеж : ВГУ, 2005. $391 \mathrm{c.}$

11. Franzke B. Romy Henfling. Interkulturelle Kompetenz Deutschland-Russland. 20 Critical Incidents mit Lösungsmustern. Bielefeld : W. Bertelsmann Verlag, 2017. $153 \mathrm{~S}$.

12. Slate E. J. Sylvia Scholl-Machl. Beruflich in den USA. Trainingsprogramm für Manager, Fach- und Führungskräfte. Göttingen : Vandenhoeck\& Ruprecht, 2006. 170 S.

13. Roth J. Eigenbilder, Fremdbilder, Zerrbilder: Zum Erscheinen des ersten russischen "Kulturknigge" // Blickwechsel. Münster, N.Y., München, Berlin : Waxman, 2003. S. 127-132.

14. Posner R. Kultursemiotik // Konzepte der Kulturwissenschaften. Hrsg. von A. Nünning und V. Nünning. Stuttgart, Weimar: J. B. Metzler, 2003. S. 39-72.

15. Anderson J. R. Kognitive Psychologie. Heidelberg; Berlin : Spectrum: Akademischer Verlag, 2001. 542 S.

16. Краткий словарь когнитивных терминов / Е. С. Кубрякова [и др.]. М. : МГУ, 1997. 245 с.

17. Болдырев Н. Н. Язык и система знаний. Когнитивная теория языка. М. : ЯСК, 2019. 480 с.

18. Hoffmann J. Das aktive Gedächtnis. Psychologische Experimente und Theorien zur menschlichen Gedächtnistätigheit. Berlin ; Heidelberg ; New York : Springer-Verlag, 1983. $264 \mathrm{~S}$.

19. Kleiber $G$. Prototypensemantik. Eine Einführung. Tübingen : Narr, 1998. 153 S.

20. Klix F. Gedächtnis. Wissen. Wissensnutzung. Berlin : Deutscher Verlag der Wissenschaften, 1984. 262 S.

21. Гришаева Л. И. Особенности использования языка и культурная идентичность коммуникантов. Воронеж : ВГУ, 2007. 262 c.

22. Dietze J. Einführung in die Informationslinguistik. Die linguistische Datenverarbeitung in der Informationswissenschaft. Leipzig : Verlag Enzyklopädie, 1989. $195 \mathrm{~S}$.

23. Гришаева Л. И. Функциональный потенциал имени собственного в медиапространстве, или «Королевство кривых зеркал» // Имя собственное в медиапространстве : кол. монография / Л. И. Гришаева [и др.]. Воронеж : Издательский дом Воронеж. гос. ун-та, 2019. C. 107-181.

24. Гришаева Л. И. Варьирование текста в коммуникации. Воронеж : НАУКА-ЮНИПРЕСС, 2020. 291 с. 


\section{REFERENCES}

1. Tsvasman L. Manipulation [manipulation]. In: Das große Lexikon Medien und Kommunikation. Hrsg. von Leo R. Tsvasman. Würzburg: Ergon-Verlag, 2006. Pp. 226-228.

2. Pugatschjow V. [Faktoren und Merkmale der Manipulation]. In: Das große Lexikon Medien und Kommunikation. Hrsg. von Leo R. Tsvasman. Würzburg: Ergon-Verlag, 2006. Pp. 228-233.

3. Merten K. Macht der Medien [power of the (mass) media]. In: Das große Lexikon Medien und Kommunikation. Hrsg. von Leo R. Tsvasman. Würzburg: Ergon-Verlag, 2006. Pp. 224-226.

4. Antos $G$. Fake News. Warum wir auf sie reinfallen. Oder: "Ich mache euch die Welt, so wie sie mir gefällt". Sprachdienst, 2017. Heft 1. Pp. 1-20.

5. Grischaewa L. I. Homo ludens, Fake News und Text, oder warum ändern sich die Textgestaltungsprinzipien? In: Russkaja germanistika: Ežegodnik Rossijskogo sojusa germanistov. T. 17: Tipologija tekstov I diskursivnyje praktiki v nemeckojasyčnom kulturnom prostranstve. M.: FLINTA, 2020. S. 24-47.

6. Grišaeva L. I., Tsurikova L. V. Teroija mežkulturnoi kommunikacii: problem, podchody, analis. Voronež: Isdatelskij dom Voronežskogo gosudarstvennogo universiteta, 2018. 505 p.

7. Grišaeva L. I., Tsurikova L. V. Vvedenije v teoriju mežkulturnoi kommunikacii. M.: Academia, 2008. Isd. 5-e. $352 \mathrm{p}$.

8. Grišaeva L. I., Tsurikova L. V. Konceptualnyje osnovy analisa mežličnostnogo vsaimodeistvija nositeleij rasnych kultur (čast 1). In: Vestnik VGU. Seria: Linguistika I mežkulturnaja kommunikacija. 2013. No. 1. Pp. 14-21.

9. Grišaeva L. I., Tsurikova L. V. Konceptualnyje osnovy analisa mežličnostnogo vsaimodeistvija nositeleij rasnych kultur (čast 2). In: Vestnik VGU. Seria: Linguistika Imežkulturnaja kommunikacija. 2013. No. 2. Pp. 30-35.

10. Strategii uspecha i factory riska v mežkulturnoi kommunikacii : kol. monografia pod. red. Grišaevoi L. I. I Tsurikovoi L. V. Voronež: VGU, 2005. 391 p.

11. Franzke B. Romy Henfling. Interkulturelle Kompetenz Deutschland-Russland. 20 Critical Incidents mit

Воронежский государственный университет

Гришаева Л. И., доктор филологических наук, профессор кафедры немецккой филологии

E-mail: grischaewa@rgph.vsu.ru

Поступила в редакичию 20 мая 2021 г.

Принята к публикаџии 15 июня 2021 г.

\section{Для циитирования:}

Гришаева Л. И. Насколько реально «избавиться от стереотипов»? (полемические заметки на полях публикаций по проблемам теории межкультурной коммуникации) // Вестник Воронежского государственного университета. Серия: Лингвистика и межкультурная коммуникация. 2021. № 3. C. 39-53. DOI: https://doi. org/10.17308/lic.2021.3/3578
Lösungsmustern. Bielefeld: W. Bertelsmann Verlag, 2017. $153 \mathrm{p}$.

12. Slate E. J. Sylvia Scholl-Machl. Beruflich in den USA. Trainingsprogramm für Manager, Fach- und Führungskräfte. Göttingen: Vandenhoeck\& Ruprecht, 2006. 170 p.

13. Roth J. Eigenbilder, Fremdbilder, Zerrbilder : Zum Erscheinen des ersten russischen "Kulturknigge". In: Blickwechsel. Münster, N.Y., München, Berlin: Waxman, 2003. Pp. 127-132.

14. Posner R. Kultursemiotik. In: Konzepte der Kulturwissenschaften. Hrsg. von A. Nünning und V. Nünning. Stuttgart, Weimar: J. B. Metzler, 2003. Pp. 39-72.

15. Anderson J. R. Kognitive Psychologie. Heidelberg; Berlin: Spectrum: Akademischer Verlag, 2001. 542 p.

16. Kratkij slovar kognitivnych terminov / Kubrjakova E. S., DEmjankov V. S., Pankraz Ju. G., Lusina L. G. M.: MGU, 1997. 245 p.

17. Boldyrev N. N. Jazyk I sistema snanij. Kognitivnaja teorija zasyka. M.: Isdatelskij Dom JaSK, 2019. 480 p.

18. Hoffmann J. Das aktive Gedächtnis. Psychologische Experimente und Theorien zur menschlichen Gedächtnistätigheit. Berlin ; Heidelberg ; New York: Springer-Verlag, 1983. $264 \mathrm{p}$.

19. Kleiber G. Prototypensemantik. Eine Einführung. Tübingen: Narr, 1998. 153 p.

20. Klix F. Gedächtnis. Wissen. Wissensnutzung. Berlin: Deutscher Verlag der Wissenschaften, 1984. 262 p.

21. Grišaeva L. I. Osobennosty ispolzovania jazuka : kul'turnaya identichnost' communikantov. Voronezh : VGU, 2007. $262 \mathrm{p}$.

22. Dietze J. Einführung in die Informationslinguistik. Die linguistische Datenverarbeitung in der Informationswissenschaft. Leipzig: Verlag Enzyklopädie, 1989. 195 S.

23. Grišaeva L. I. Funkcionalnyi potential imeni sobstevennogo v mediaprostranstve, ili "Koro;evstvo krivych serkal". In: Imja sobstvennoke v mediaprostransve : kol. monografia / L. I. Grišaeva, O. O. Boriskina, N. A. Fenenko, V. N. Ababij, V. G. Šimko. Voronež: Isdatelskij Dom Voronežskogo gosudarstvennogo universiteta, 2019. Pp. 107181.

24. Grišaeva L. I. Variirovanije teksta v kommunikacii. Voronež: NAUKA-JUNIPRESS, 2020. 291 p.

Voronezh State University

Grishaeva L. I., Doctor of Philology, Professor of the German Philology Department

E-mail: grischaewa@rgph.vsu.ru

Received: 20 May 2021

Accepted: 15 June 2021

\section{For citation:}

Grishaeva L. I. How realistic is it to "get rid of stereotypes"? (polemic notes in the margins of publications on the major issues of the theory of intercultural communication). Proceedings of Voronezh State University. Series: Linguistics and Intercultural Communication. 2021. No. 3. Pp. 3953. DOI: https://doi.org/10.17308/lic.2021.3/3578 